NBER WORKING PAPER SERIES

\title{
INTERNATIONAL AND DOMESTIC COLLATERAL CONSTRAINTS IN A MODEL OF EMERGING MARKET CRISES
}

\author{
Ricardo J. Caballero \\ Arvind Krishnamurthy \\ Working Paper 7971 \\ http://www.nber.org/papers/w7971 \\ NATIONAL BUREAU OF ECONOMIC RESEARCH \\ 1050 Massachusetts Avenue \\ Cambridge, MA 02138 \\ October 2000
}

We thank Daron Acemoglu, David Backus, Craig Burnside, V.V. Chari, Bhagwan Chowdhry, Oliver Hart, Bengt Holmstrom, Andres Velasco, Luigi Zingales, two anonymous referees and seminar participants at the Fed (Board of Governors), Harvard, IMF, MIT, Northwestern, UCLA, EFG-NBER meetings, WFA meetings, the CEPR Summer Symposium on Financial Markets (Gerzensee), and the LACEA/UTDT Summer Camp in International Economics and Finance (Buenos Aires) for their comments and suggestions. Ricardo Caballero thanks the NSF for financial support, and the AEI and Research Department at the IMF, where part of this work was accomplished, for their hospitality and support. This is an extensively revised version of "Emerging Market Crises: An Assets Market Perspective," (1999). The views expressed in this paper are those of the authors and not necessarily those of the National Bureau of Economic Research.

(C) 2000 by Ricardo J. Caballero and Arvind Krishnamurthy. All rights reserved. Short sections of text, not to exceed two paragraphs, may be quoted without explicit permission provided that full credit, including $($ ) notice, is given to the source. 
International and Domestic Collateral Constraints in a Model of Emerging Market Crises

Ricardo J. Caballero and Arvind Krishnamurthy

NBER Working Paper No. 7971

October 2000

JEL No. G00, E4, F3

\begin{abstract}
We build a model of emerging markets crises which features two types of collateral constraints. Firms in a domestic economy have limited borrowing capacity from international investors. They also have limited borrowing capacity with respect to each other. We study how the presence of and changes in these collateral constraints affect financial and real variables. A binding international constraint in the aggregate leads to a sharp rise in interest rates and fire sales of domestic assets, while limited domestic collateral can lead to wasted international collateral. These two collateral constraints can interact in important ways. The first is disintermediation: a fire sale of domestic assets causes banks to fail in their function of reallocating resources across the economy leading to wasted international collateral. The second is a dynamic effect. We show that firms in an economy with limited domestic collateral and a binding international collateral constraint will not adequately precaution against adverse shocks, increasing the severity of these shocks. Our approach is distinctive in that, while much of the literature on the role of financial constraints in macroeconomics draws their insights within either of these collateral deficiencies, we argue that their static and dynamic interactions have important consequences for emerging markets' performance.
\end{abstract}

Ricardo Caballero

Department of Economics

MIT

50 Memorial Drive, E52-252A

Cambridge, MA 02142

and NBER

caball@mit.edu
Arvind Krishnamurthy

Kellogg Graduate School of Management

Finance Department

2001 Sheridan Road., Leverone

Evanston, IL 60208

a-krishnamurthy@nwu.edu 


\section{Introduction}

The recent episodes of emerging market crises have increased awareness, both in the academic and policy circles, that financial factors play a central role in macroeconomic performance. In many accounts, the sudden stop and then withdrawal of international capital flows was the spark that set off these crises. The IMF asserts that the ensuing declines in asset prices and exchange rates were "well beyond what was justified by any reasonable reassessment of economic fundamentals, even in the light of the crisis." (IMF World Economic Outlook, May 1998, p.4.) Falling asset prices compromised weak domestic banking systems, while widespread bankruptcies among over-leveraged firms all contributed to significantly aggravating the downturn.

While often blurred, there are essentially two distinct types of financial constraints models in the macroeconomics literature. In the first group, best represented in the "developed economies" literature (e.g. Bernanke and Gertler 1989, Kiyotaki and Moore 1997, Holmstrom and Tirole 1997), widespread microeconomic financial constraints either among firms or banks limit a country's ability to reallocate resources, exacerbating the amplitude and costs of recessions. In the second group, as emphasized in the "emerging economies" literature, a constraint on the aggregate borrowing of a country binds and leads to real dislocations. Examples include Bulow and Rogoff (1987) and Atkeson and Rios-Rull (1996) for explicit models of this international collateral constraint, or Calvo (1998), for an implicit model of it.

The purpose of this paper is to construct a simple equilibrium model to account for some of the stylized facts surrounding emerging markets' crises, and thereby shed light on the respective roles of these two types of financial constraints. The analysis allows us to delineate the distinct roles of these financial constraints, as well as uncover important interaction effects. Firms in our model have limited international collateral that determines the amount of financing that foreign investors extend to these firms. Concretely, we imagine that international collateral consists of export sector revenues that international investors can seize in the event of loan default. We also assume that firms within an economy have domestic collateral that determines how much financing they can obtain from each other. We think of real estate as a prime example of domestic collateral.

A tightening of the international constraint at the country level can generate a large rise in domestic interest rates and a fire sale of domestic assets, and a corresponding contraction in real activity. The binding aggregate constraint means the economy runs out of resources to finance all investment needs. The rise in interest rates reflects the high shadow value of

these resources. An alternative channel behind a real contraction is a shortage of domestic collateral. Even when the economy has sufficient resources in the aggregate, if firms in 
need of funds have insufficient domestic collateral they will not be able to access these resources. These two collateral constraints can interact via a credit crunch. If the banking sector is responsible for reallocating resources across the economy, and this capacity is compromised by a fall in asset prices, the tightening international financial constraint leads to a contraction in effective domestic collateral.

The interaction can also occur in the reverse direction. A puzzling aspect of recent crises are actions taken by the private sector that leave the economy more vulnerable to adverse shocks. A typical example is the large amount of foreign liabilities that firms in Asia contracted during the years preceding the crises. We show that the interaction between limited domestic collateral and the international collateral constraint, in a dynamic setting, causes firms to undervalue international collateral. That is, firms systematically take actions that leave them with too little international collateral during crises, exacerbating the effects of adverse shocks.

The economics behind this under-insurance result arises from the observation that limited domestic collateral creates a wedge between the internal return on investment for a domestic firm and the external return that is promised to an outside investor (i.e. another domestic). In a crisis the economy is short of international collateral. Abating the crisis requires an ex-ante decision to retain some international collateral - for example by contracting less foreign debt ex-ante. However if there is a wedge between internal and external returns on investment, the private valuation of this international collateral will be less than its social value.

The usefulness of our analysis is two-fold. First, while we are not unique in noting some of the financial factors illustrated by the model, we do provide a fairly simple and unified framework in which to clarify these mechanisms. Second, the model uncovers the dynamic undervaluation result, which should be helpful in the analysis of ex-ante precautionary questions - both among the private sector, and to guide policy actions.

Relation to the literature. As we mentioned above, microeconomic borrowing constraints arise in many parts of the literature on financial constraints in macroeconomics, and aggregate collateral constraints arise most explictly in the sovereign debt literature. Since in the latter literature default and its costs are mostly modeled as a country-wide phenomenon, the question immediately arises on whether the domestic private sector internalizes the effect of their actions on the likelihood of these events. Bardhan (1967), Harberger (1985) and Aizenman (1989) advocated taxing capital flows on the grounds that individual agents do not pay for the increase in a country's average cost of capital brought about by their international indebtedness. While our result on collateral undervaluation is related to theirs, our externality stems from imperfections in the domestic financial system rather than from the country's monopsony power in international financial markets.

The modeling approach we follow owes to Diamond and Dybvig's (1983) canonical model 
of liquidity and particularly to Holmstrom and Tirole (1998)'s departure from this model in the context of firms. As in that paper, firms in our economy receive a production shock that they must cope with by mortgaging collateral in order to borrow additional funds. The latter can be obtained from other domestic firms or directly from international investors. Analogously, firms in the model of Holmstrom-Tirole can borrow funds either from other firms in the corporate sector or directly from savers. Intermediation renders the first transaction frictionless in Holmstrom-Tirole and their macroeconomic analysis focuses on the implementation and efficiency of the second transaction. In contrast, both transactions encounter frictions in our model.

Our underprovision of collateral results are analogous to the free rider problems and underprovision of liquidity studied in the banking literature (see Jacklin 1987, Bhattacharya and Gale 1987, Allen and Gale 1997). However, the source of the externality behind this inefficiency in our model is the endogenous result of borrowing constraints, while theirs is the exogenous divergent ex-post valuation of liquidity by consumers. The literature on crises has focused on models of bank runs and their key sequential service constraint (Diamond and Dybvig 1983, Goldfajn and Valdes 1998, and Chang and Velasco 1998). While we do believe that bank failures and runs can aggravate crises, as we discuss in section 5, our model points out that the basic features of crises and their prelude arise even when no agent or institution is committed to supply liquidity. Moreover, the fire sale mechanism we emphasize boosts and feeds from the likelihood of banking crises themselves. Finally our asset pricing implications arise from market segmentation. Allen and Gale (1994) and Merton (1987) have noted the impact of segmentation on asset prices.

Outline. Section 2 follows with a description of the model and the different regions that arise from the existence of two types of financial constraints. Section 3 focuses on the "wasted collateral" region, where the domestic-microeconomic constraints are binding but not the international-aggregate constraint. Section 4 is the core of the paper, as it adds the international financial constraint and shows the dynamic feedback from the domestic

to the international constraint. Section 5 introduces banks and presents an example of the reverse feedback, that is from the international financial constraint to the domestic constraint. Section 6 concludes, and is followed by an appendix.

\section{A Time-to-build model with limited international and do- mestic collateral}

\subsection{Preferences, Technology and Financial Constraints}

Time. The world lasts three periods, $t=0,1,2$. In date 0 , agents make real investment and borrowing decisions. Adverse shocks may affect production at date 1. Agents must 
again making borrowing choices to cope with these shocks. At date 2, all returns are realized, debts are repaid, and consumption takes place.

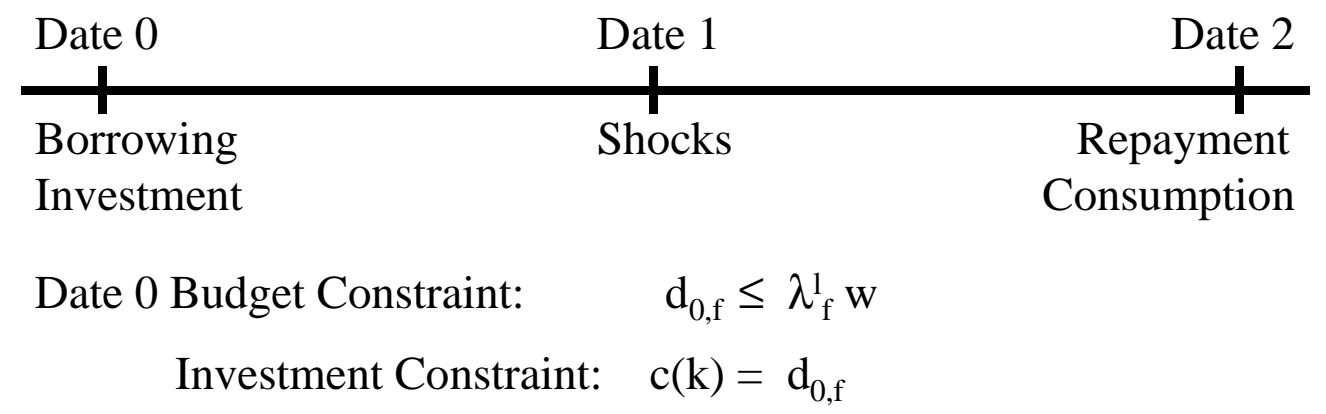

\section{Production: Time-to-build}

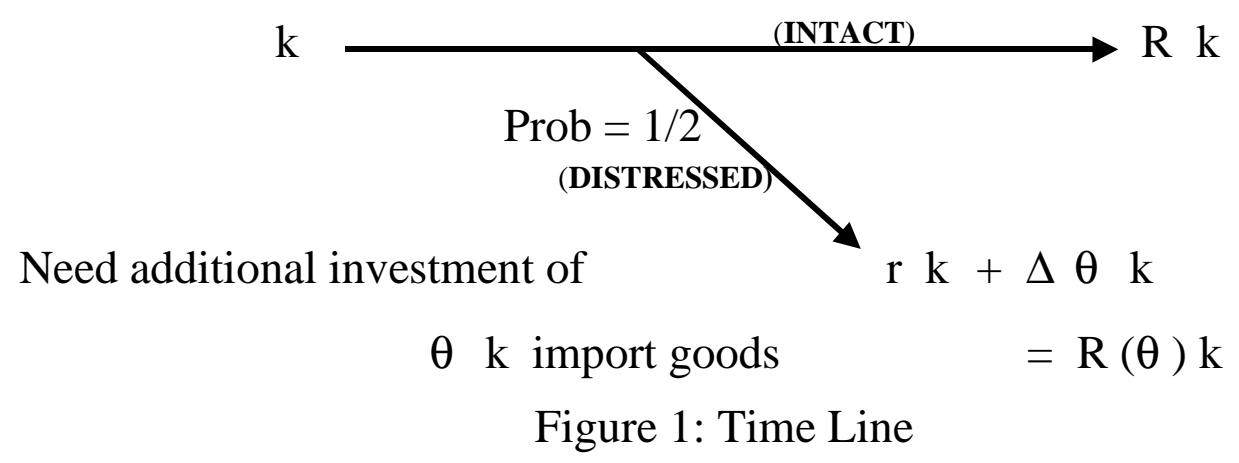

Agents and heterogeneity. The economy has a single consumption good. There are two types of agents: (i) a continuum of unit measure of domestic entrepreneurs-consumers (henceforth, domestics) with linear preferences over date 2 consumption of a single (tradeable) good, and (ii) foreign financiers (henceforth, foreigners) with large endowments who also value consumption of the single good at the final date only. Agents have frictionless storage technologies so the international gross interest rate is one.

Production. Domestics have no goods at date 0 and date 1. As we shall describe shortly, all of their endowment is in the form of "international collateral" goods at date 2 . In order to produce, domestics must borrow and import goods from foreigners. Production has a time-to-build aspect. Investments are made at dates 0 and 1, and output is realized at date 2. Creating $k$ units of capital requires a date 0 investment of $c(k)$ units of imported goods. The function $c(k)$ is assumed to be strictly increasing, convex and positive, to guarantee an interior solution.

We capture the normal churn of the economy, with its implied domestic heterogeneity, with a simple Bernoulli process. At date 1, half of the firms (randomly selected) are spared of further investment and go on to produce $R k$ units of goods at date 2 ("intact firms"). 
The rest ("distressed firms") experience a productivity fall to $r<R$. This can be offset by reinvesting a fraction $\theta \leq 1$ of $k$, in units of the imported good, in order to realize output at date 2 of:

$$
(r+\theta \Delta) k \leq R k
$$

where,

$$
\Delta \equiv R-r .
$$

Financing and Collateral. In order to explore the financial problems that concern us we introduce borrowing constraints on domestic firms. Before doing so, however, we must deal with a subtle issue. Despite the linearity of preferences, insurance-demand arises as soon as date 1 financial constraints are introduced. There are essentially two classes of insurance contracts to consider. The first one is with respect to idiosyncratic shocks. Firms could in principle sign contracts at date 0 , contingent on the realization of types, whereby resources were always transferred from intact to distressed firms. In reality these contracts are seldom perfect due to asymmetric information, and in our model we capture this imperfection in its extreme form:

Assumption 1 (Non-observability of Production Shock) The production shock at date 1 is idiosyncratic. The identity of firms receiving the shock is private information.

But private information does not rule out signing insurance contracts with respect to aggregate shocks. However, introducing these contracts would dampen the effects of aggregate shocks, but would not undo any of our main qualitative results. ${ }^{1}$ Thus, for simplicity, we only analyze uncontingent debt contracts.

We assume that each domestic agent is endowed at date 0 with some date 2 goods that are international collateral - e.g., the present value of export sector receivables. This endowment is all that can be pledged to foreigners to secure debt repayments. Thus we make the extreme assumption that none of the output from domestic production is acceptable collateral to foreigners.

Denote the amount of international collateral for a domestic as $\lambda_{f}^{\omega} w$. There are two states of the world at date $1, \omega \in\{l, h\}$. State $l$ occurs with probability $\pi^{l}$, while state $h$ occurs with probability $\pi^{h}=1-\pi$. Across all domestic agents, there is less collateral in the $l$ state than the $h$ state,

$$
0<\lambda_{f}^{l} w<\lambda_{f}^{h} w
$$

\footnotetext{
${ }^{1}$ See Caballero and Krishnamurthy $(1999,2000 \mathrm{~b})$ for an analysis of contingency. Also, see the former for the slightly more general case (but identical in equilibrium) where foreigners hold domestic collateral from date 0 to 1 .
} 
Since only $\lambda_{f}^{\omega} w$ is international collateral, foreigners will only extend financing up to this amount. The effect of the aggregate shock is to tighten the international borrowing constraint in the $l$-state and therefore curtail production and refinancing options at date $1 .{ }^{2}$

\section{Assumption 2 (Foreign debt and international collateral)}

Foreign lenders require international collateral to back all promised repayments. These repayments are assumed to be uncontingent on the aggregate shock at date 1 . Let $d_{0, f}$ and $d_{1, f}^{\omega}$ denote foreign debt contracted at dates 0 and 1 (in state $\omega$ ), respectively. Then,

$$
\begin{gathered}
d_{0, f} \leq \lambda_{f}^{l} w=\min _{\omega}\left\{\lambda_{f}^{\omega} w\right\} \\
d_{1, f}^{\omega} \leq \lambda_{f}^{\omega} w-d_{0, f} .
\end{gathered}
$$

While the international interest rate is pinned down at one by foreigners, as we will see later the domestic interest rate (the only equilibrium price in our model) may rise above this value. This interest rate applies to assets which are valued by domestics but not by foreigners. This asymmetric valuation is due to our assumption that foreigners cannot seize any of the goods from domestic production, while domestics can. The parameter $\lambda_{d}$ controls how much of this production is domestic collateral and represents the degree of development of domestic financial markets.

\section{Assumption 3 (Domestic debt and collateral)}

A domestic lender can only be sure that a firm will produce $\lambda_{d} r k$ units of goods at date 2. Any excess production based on reinvestment at date 1 is neither observable nor verifiable. Let $L^{\omega} \geq 1$ denote the domestic (gross) interest rate in state $\omega$, then domestic lending at date 1 must satisfy,

$$
d_{1, d}^{\omega} \leq \lambda_{d} \frac{r k}{L^{\omega}}+\left(\lambda_{f}^{\omega} w-d_{0, f}-d_{1, f}^{\omega}\right), \quad 0 \leq \lambda_{d} \leq 1 .
$$

Since all domestic firms are identical at date 0, the domestic debt market is not accessed at date 0 . Our assumption plays a role only at date 1 , when intact firms become domestic lenders to the distressed firms.

Finally we need to make a technical assumption on returns to date 1 reinvestment versus date 0 reinvestment, in order to ensure that firms do not saturate their budget constraint at date 0 ,

$$
\Delta>\frac{R+r}{2 c^{\prime}\left(\lambda_{f}^{l} w\right)}>1
$$

\footnotetext{
${ }^{2}$ Our assumption on the tightening of the international collateral constraint in the $l$-state can be interpreted in a number of ways. This is a terms of trade shock, a rise in the international interest rate, or a rise in the premium that foreign investors require for lending to emerging markets. We are agnostic on the source of the shock.
} 


\subsection{Optimization and Equilibrium}

The problem can be solved by backward induction.

Date 1 problem. Date 0 decisions result in firms arriving at date 1 with installed capital of $k$ and foreign debt of $d_{0, f}$. At date 1 , a firm that receives a shock is distressed (S), while a firm that escapes the shock is intact (I). The balance sheet of a domestic firm has assets of $r k$ units of domestic collateral and $w$ units of international collateral, and foreign debt of $d_{0, f}$.

Suppose that date 0 choices of $\left(k, d_{0, f}\right)$ have been made. Consider the problem of a distressed firm in raising funds at date 1 to alleviate its production shock. Saving production units is an investment that requires one unit of imported goods, and returns $\Delta$ units of goods at date 2 . Since the return on this investment of $\Delta$ always exceeds the international interest rate of one, the firm will turn to the international debt market for financing. It can raise at maximum, $\lambda_{f}^{\omega} w-d_{0, f}$, from this market. If, $k>\lambda_{f}^{\omega} w-d_{0, f}$ then the firm will have to turn to other sources for finance. Since intact firms still have excess international collateral, a distressed firm can borrow from the intact firm against its domestic collateral and import additional goods. Through this "credit chain," the distressed firm is able to aggregate the international collateral of the economy and pledge this to foreigners to raise resources for date 1 reinvestment. As long as $\Delta>L^{\omega}$ the firm will borrow as much as it can (or needs) in the domestic debt market. The maximum amount of funds (in units of import goods) that can be raised, after exhausting foreign resources, is

$$
d_{1, d}^{\omega} \leq \frac{\lambda_{d} r k}{L^{\omega}}
$$

We shall refer to this inequality as the domestic collateral constraint.

We can then write the problem of a distressed firm as,

$$
\begin{array}{lll}
(P 1) \quad V_{s}^{\omega} \equiv \max _{\theta_{n},}^{\omega}, d_{1, f}^{\omega}, d_{1, d}^{\omega} & \lambda_{f}^{\omega} w+(r+\Delta \theta) k-d_{0, f}-d_{1, f}^{\omega}-L^{\omega} d_{1, d}^{\omega} \\
\text { s.t. } & (i) & d_{1, f}^{\omega}+d_{0, f}+d_{1, d}^{\omega} \leq \lambda_{f}^{\omega} w+\frac{\lambda_{d} r k}{L^{\omega}} \\
& (\text { ii }) & d_{1, f}^{\omega}+d_{0, f} \leq \lambda_{f}^{\omega} w \\
& (\text { iii }) & \theta^{\omega} k=d_{1, f}^{\omega}+\frac{d_{1, d}^{\omega}}{L^{\omega}} \\
& (\text { iv }) & \theta^{\omega} \leq 1 .
\end{array}
$$

Constraints $(i)$ and $(i i)$ are balance sheet constraints (net marketable assets greater than liabilities) as perceived by domestic and foreign lenders, respectively. Constraint (iii) reflects that new investment must be fully paid with the resources received by the firm at date 1 in taking on debts of $d_{1, f}^{\omega}$ and $d_{1, d}^{\omega}$. Constraint $(i v)$ is purely technological.

An intact firm at date 1 has only one decision: how much finance will it extend to the distressed firm. Suppose that the firm borrows import goods against its international 
collateral and lends $x_{1, d}$ of these goods in the domestic market at the interest rate of $L^{\omega}$. Then,

$$
\begin{array}{lll}
(P 2) & V_{i}^{\omega} \equiv \max _{x_{1, d}^{\omega}} & \lambda_{t}^{\omega} k_{t}+R k+L^{\omega} x_{1, d}^{\omega}-x_{1, d}^{\omega} \\
& & d_{0, f}+\frac{x_{1, d}^{\omega}}{L^{\omega}} \leq \lambda_{f}^{\omega} w
\end{array}
$$

Date 0 problem. At date 0, a firm looking forward to date 1 can expect to find itself as either distressed or intact, and in either the $h$ or the $l$ aggregate state of the world. Thus the decision at date 0 is,

$$
\begin{aligned}
(P 3) \max _{k, d_{0, f}} & \sum_{\omega \in\{h, l\}} \pi^{\omega} \frac{1}{2}\left(V_{s}^{\omega}+V_{i}^{\omega}\right) \\
\text { s.t. } & d_{0, f} \leq \lambda_{f}^{l} w \\
& c(k)=d_{0, f} .
\end{aligned}
$$

where $\pi^{\omega}$ represents the probability that state $\omega$ occurs.

Equilibrium. Market clearing in the domestic debt market at date 1 (capital letters denote aggregate quantities) requires that the aggregate amount of domestic debt taken on by distressed firms is fully funded by intact firms:

$$
\begin{aligned}
D_{1, d}^{\omega} & =\frac{1}{2} d_{1, d}^{\omega} \\
X_{1, d}^{\omega} & =\frac{1}{2} x_{1, d}^{\omega} .
\end{aligned}
$$

Therefore, market clearing,

$$
D_{1, d}^{\omega}=X_{1, d}^{\omega}
$$

determines the gross interest rate $L^{\omega}$.

An equilibrium of this economy consists of date 0 and date 1 decisions, $\left(k, d_{0, f}\right)$ and $\left(\theta^{\omega}, d_{1, f}^{\omega}, d_{1, d}^{\omega}, x_{1, d}^{\omega}\right)^{\omega \in\{l, h\}}$, respectively, and prices $\left(L^{\omega}\right)^{\omega \in\{l, h\}}$. Decisions are solutions to the firms' problems (P1), (P2), and (P3) given prices. At these prices, the market clearing condition (2) holds.

\subsection{Regions}

With the basic setup behind us, we turn to characterizing equilibrium at date 1 . Because of the linearity in preferences and returns to reinvestment, the decision problems end up yielding corner solutions, and equilibrium falls into one of four regions.

Let us begin with the case that $\Delta>L^{\omega}>1$. Consider the problem of a distressed firm at date 1 , as stated in (P1). Since $\Delta$ exceeds both the international and domestic interest rates, the firm will borrow as much as it can (or needs) from the domestic and international investors. The maximum amount of funds that the firm can raise is,

$$
\lambda_{f}^{\omega} w-d_{0, f}+\frac{\lambda_{d} r k}{L^{\omega}}
$$


Since $L^{\omega}>1$, intact firms will import goods of $\lambda_{f}^{\omega}-w$ from foreign investors and lend these to the distressed firms. Then equilibrium requires that,

$$
\frac{1}{2} \frac{\lambda_{d} r k}{L^{\omega}}=D_{1, d}^{\omega}=X_{1, d}^{\omega}=\frac{1}{2}\left(\lambda_{f}^{\omega} w-d_{0, f}\right) .
$$

Solving, yields

$$
L^{\omega}=\frac{\lambda_{d} r k}{\lambda_{f}^{\omega} w-d_{0, f}} .
$$

This is the first case. In this scenario, it is easy to see that since all of the intact firms excess collateral is transferred to the distressed firms, there is full collateral aggregation. Thus total reinvestment is,

$$
\theta^{\omega} k=2\left(\lambda_{f}^{\omega} w-d_{0, f}\right)
$$

The second case follow closely from the above expressions. Note that it is algebraically possible that this equation requires that $\theta^{\omega} \geq 1$. Economically this means that there is sufficient collateral for all distressed production units to be restructured, and therefore firms will choose $\theta^{\omega}=1$. Since there is excess supply in the domestic debt market, $L^{\omega}=1$ (equal to the international interest rate).

The difference between these last two cases is that in the second, the economy reinvests less than its international collateral. We can define the international collateral constraint as,

$$
\theta^{\omega} k \leq 2\left(\lambda_{f}^{\omega} w-d_{0, f}\right) .
$$

If the constraint binds the economy must be aggregating all of its international collateral, and therefore $L^{\omega}>1$. When the constraint does not bind, it must be that $L^{\omega}=1$.

The final case is when $L^{\omega}$ is equal to one, because $\lambda_{d}$ is low and actually (1) binds. That is, suppose that $\theta^{\omega}<1$, but

$$
\lambda_{d} r k<\lambda_{f}^{\omega} w-d_{0, f}
$$

In this case domestic distressed firms lack sufficient collateral to compensate intact firms for their international collateral and the domestic interest rate falls to one. Collateral constrained demand depresses the equilibrium interest rate.

Figure 2 illustrates each of these scenarios. Before describing the figure, let us define the international spread, $s_{f}^{\omega}$, as

$$
s_{f}^{\omega} \equiv L^{\omega}-1 \text {. }
$$

Likewise, let us define the domestic spread, $s_{d}^{\omega}$ as,

$$
s_{d}^{\omega} \equiv \Delta-L^{\omega} .
$$

This is the difference between the marginal product of investment for a distressed firm and the interest rate that it pays to its lenders. It is the wedge between internal and external returns that typically arises in models with credit constraints. 


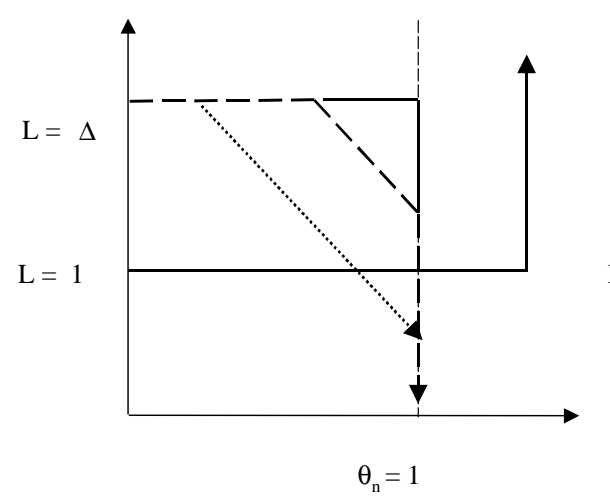

Panel (a) : Regions I and II

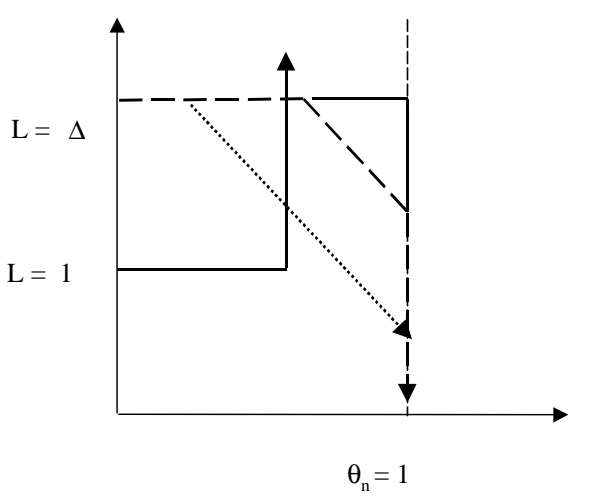

Panel (b) : Regions III and IV

Figure 2

The supply curve in both panels is the supply of international collateral in the economy. It is horizontal at the international interest of $L=1$ upto the point that the international collateral constraint binds, and then it turns vertical. The panel on the left represents $\lambda_{f}^{l}$, while that on the right is $\lambda_{f}^{h}$. The demand curve for funds can be in one of two situations. First, the horizontal part of the curve traces out the marginal product of reinvestment for a distressed firm. Demand for funds falls below this curve when the domestic collateral constraint begins to bind. The amount of domestic collateral for a distressed firm is,

$$
\frac{\lambda_{d} r k}{L^{\omega}}
$$

Thus as $L^{\omega}$ starts to fall the collateral is worth more and the collateral constraint gradually loosens. This traces the diagonal downwards.

The demand curve in both panels illustrates a case of higher and lower $\lambda_{d}$. The lower and more constrained demand curve is a lower $\lambda_{d}$, representing less domestic financial market development.

Proposition 1 summarizes the main results up to this point:

Proposition 1 (Regions). The economy can be in one of four regions at date 1, depending on which of the two collateral constraints, (1) and (4), bind. 
- Region I occurs when both the international collateral constraint (4) and the domestic collateral constraint (1) are slack. In this case, both international and domestic spreads are zero and there is full project completion. $s_{d}^{\omega}=s_{f}^{\omega}=0, \theta^{\omega}=1$.

- Region II occurs when the international constraint is slack but the domestic constraint is binding. International spreads remain zero, however domestic spreads are positive as the economy fails to aggregate all of its collateral resulting in some projects being downsized. $s_{d}^{\omega}>0, s_{f}^{\omega}=0, \theta^{\omega}<1$.

- Region III occurs when the international constraint is binding but the domestic constraint is slack. International spreads jump to $\Delta-1$, while domestic spreads remain at zero. The economy aggregates all of its collateral, however there is insufficient aggregate resources and some projects are downsized. $s_{d}^{\omega}=0, s_{f}^{\omega}>0, \theta^{\omega}<1$.

- Region IV occurs when both the international constraint and the domestic constraint are binding. Both, international spreads and domestic spreads are positive and some projects are downsized. $s_{d}^{\omega}>0, s_{f}^{\omega}>0, \theta^{\omega}<1$.

\subsection{Discussion of main assumptions}

We have assumed a friction that prevents a domestic entrepreneur from borrowing fully up to his output from another domestic. Investment at date 0 produces $r k$ goods at date 2 , and depending on the realization of shocks and reinvestment, an additional $\Delta k$ of output. In a well functioning domestic financial market - i.e. if there were no frictions in borrowing from another domestic - both the $r k$ and the $\Delta k$ of output could be sold to obtain funds for investment. In assuming that only $\lambda_{d} r k$ is observable and verifiable, we have restricted claims sold to another domestic to this amount. ${ }^{3}$ The modeling of this borrowing constraint is not unusual. It is most similar to the limited collateral constraint of Kiyotaki and Moore (1997), or the limited enforcement constraint of Kehoe and Levine (1993). Kiyotaki and Moore (1997) assume that output is not verifiable, but that physical collateral (land) is. Our $\lambda_{d} r k$ is akin to their collateral. Holmstrom and Tirole (1998) develop a model with an ex-ante unobserved effort choice where a fraction of output has to be paid as a rent to the entrepreneur so that he exerts effort. While our model does not have ex-ante moral hazard, it shares the feature that a fraction of output (i.e. $\Delta k$ ) can never be promised to a lender. Indeed, any model with borrowing constraints will share the feature that some fraction of future output is unpledgeable.

\footnotetext{
${ }^{3}$ Purely from a modeling standpoint, it is worth pointing out that $\lambda_{d}=1$ does not correspond to fully developed domestic markets. In a perfect capital market, one would expect that all of $R k$ would count as collateral. In Caballero and Krishnamurthy (1999) we model domestic collateral as $\lambda_{d}(r+\theta \Delta) k$. In this case $\lambda_{d}=1$ will correspond to the perfect capital market case.
} 
While the modeling of the domestic borrowing constraint is fairly standard in the literature on credit constraints, the asymmetry in the borrowing constraint between domestics and foreigners is unusual. $r k$ cannot be borrowed against from foreigners, while it can from domestics. First of all, there is empirical support for this assumption. For example, Mexico, during the 94-95 crisis, used its oil revenues as collateral to back the liquidity package that it received. In many instances the bias is directly justified by mandates on foreign institutional investors (e.g. limits on real estate investments, see Blommestein, 1997). ${ }^{4,5}$ Theoretically, the assumption is most similar to that of the sovereign debt literature. For example Eaton and Gersovitz (1981), Bulow and Rogoff (1989) build models of sovereign debt renegotiation around the question of what international lenders can threaten sovereign countries with in the event of a default. In this literature, debt is limited by international collateral, which is typically taken to be some fraction of exports. In Atkeson and Rios-Rull (1997) a crisis occurs when this international collateral constraint becomes tighter for a country. On the other hand, the sovereign debt literature typically just imposes international collateral as an aggregate constraint. We take a microeconomic perspective by assuming that $w$ is held by individual agents in the economy who can trade it among themselves and with foreigners.

\section{$3 \quad$ Wasted international collateral}

The only one of the regions in the previous section where no credit constraints were binding is region I. We shall henceforth assume that in the $h$ state, the economy finds itself in region I. Constraints are assumed to arise in the $l$ state. There are (as we shall make clear) two regions of most interest. In this section we shall assume that the $l$ state puts the economy in region II, while in the next section, we shall discuss region IV.

\footnotetext{
${ }^{4}$ Of course there are important exceptions (e.g. "too big to fail" utilities), but see, e.g., Kang and Stulz (1997) for systematic Japanese evidence showing that, for small firms, those that are export oriented are favored by foreign investors. See, e.g. Blommestein (1997), for a discussion of how real estate and other assets considered highly illiquid or exposed to exchange risk are generally avoided (sometimes by mandate) by foreign institutional investors. Interestingly, the very few exceptions to the sovereignty principle, by which the rating on debt issued by a country's corporate sector is bounded from above by that country's government debt rating, are for companies which belong to the export sector.

${ }^{5}$ The September 1998 report on the Asian crisis by the World Bank, describes firms that borrow in foreign currency as "predominantly large exporting firms with ties to foreign companies, and they have better adjusted to the crisis..." (box 4.3, page 62). The 1997 Industrial Survey in Thailand reflected that of those firms that borrow in foreign currency, 88 percent export, have an average of 818 employees, a debtequity ratio of 3.12, a relatively high capacity utilization and optimism during the crisis, 70 and 37 percent respectively. The same statistics for firms that do not borrow in foreign currency (75 percent of firms) are: 46 percent, 139 employees, 2.36, 61 percent and 19 percent. See Dollar and Hallward-Dreimeier (1998).
} 


\subsection{Micro-economic credit constraints}

In region II the economy fails to aggregate its international collateral. The borrowing constraint on a domestic firm is,

$$
d_{1, f}^{\omega}+d_{1, d}^{\omega} \leq \lambda_{d} r k+\lambda_{f}^{\omega} w-d_{0, f}
$$

Interestingly, there is essentially no difference between domestic and international collateral. Adding one unit of domestic collateral to a distressed firm's balance sheet would be equivalent to adding one unit of dollar collateral. Alternatively, even if foreigners accepted the $\lambda_{d} r k$ as collateral for international loans, the outcome would be the same. Thus, the aggregate collateral constraint does not play any role in this economy.

To us this case represents the situation of credit constraints that is most common in developed economies. At the micro-economic level, firms that have poor collateral are unable to borrow to meet their investment needs. There is a wedge $\left(s_{d}>0\right)$ between internal and external returns. Bernanke and Gertler (1989) and Kiyotaki and Moore (1997) are models of this environment.

One could also interpret the wasted collateral region as a "credit crunch." For example if a banking sector was responsible for evaluating the collateral of distressed firms in order to make loans to these firms, and this banking sector was compromised so that loans were cut back, again the economy would fail to aggregate all of its collateral and we would end up with $s_{d}>0$. Holmstrom and Tirole (1997) discuss this case. We shall return to a variant of their credit crunch model in section 5 .

There are two different ways to think about interest rates and spreads. In our setting all loans are fully collateralized, thus they are default free. Riskless interest rates - that is the rate of return on fully collateralized lending - is $L$, which is one. If we were to allow risky loans with default, as domestic collateral worsens (i.e. $\lambda_{d}$ falls), the interest rate on these loans would rise to reflect the growing chance of default. This could also be interpreted as rising spreads. We have already noted the wedge in lending of $s_{d}=\Delta-L$. We could also define a credit spread as the default premium on lending to distressed firms with poor collateral. If the face value on a defaultable loan is set at $\Delta k$, but the loan is collateralized

only by $\lambda_{d} r k$, then the credit spread is $\frac{\Delta}{\lambda_{d} r}-1$. This term also increases as $\lambda_{d}$ falls. By focusing on fully collateralized loans we isolate the effect that lending to firms with poor collateral is bad (or not as good) business, while ignoring the realistic - but less central for our purpose - effect that poor collateral induces default premia.

Comparing across the $h$ and $l$ states, one can see that riskless interest rates are the same, because in the $l$ state, despite the marginal product of investment being high, the lack of collateral of the investing firms means that effective investment demand is low. Low 
investment demand, low interest rates, and high interest rate spreads are common symptoms of a developed economy recession (e.g. Japan).

\subsection{Date 0 problem and Efficiency}

Let us now briefly characterize the efficiency aspects of the decentralized equilibrium. Among other things, this will help us understanding more fully the precise nature of the pecuniary externality described in section 4 .

In both, $h$ and $l$ states, an intact firm's date 2 profits are,

$$
V_{i}^{\omega}=R k+\lambda_{f}^{\omega} w-d_{0, f}
$$

In the $h$ state, the distressed firm achieves full project completion so that date 2 profits are,

$$
V_{s}^{h}=R k-k+\lambda_{f}^{h} w-d_{0, f}
$$

On the other hand, in the $l$ state, since the collateral constraints bind,

$$
\theta^{l} k=\lambda_{d} r k+\lambda_{f}^{l} w-d_{0, f}
$$

This gives us that profits are,

$$
V_{s}^{l} r k+(\Delta-1) \theta^{l} k+\lambda_{f}^{l} w-d_{0, f}=r k+\lambda_{d} r k(\Delta-1)+\Delta\left(\lambda_{f}^{l} w-d_{0, f}\right) .
$$

These last four expressions can be combined in the date 0 problem for a firm:

$$
\begin{aligned}
\text { (P4) } \max _{k, d_{0, f}} & \sum_{\omega \in\{l, h\}} \pi^{\omega} V^{\omega} \\
\text { s.t. } & V^{h}=\lambda_{f}^{l} w-d_{0, f}+R k-k / 2 \\
& V^{l}=\frac{\Delta+1}{2}\left(\lambda_{f}^{l} w-d_{0, f}\right)+\frac{R+r}{2} k+\lambda_{d} r k \frac{\Delta-1}{2} \\
& c(k)=d_{0, f} \\
& d_{0, f} \leq \lambda_{f}^{l} w
\end{aligned}
$$

Since $c(k)$ is strictly convex and the objective is linear, (P4) defines a unique optimum.

\section{Proposition 2 (Financial market development and "Underinvestment")}

A decrease in $\lambda_{d}$ has the following effects on equilibrium: (i) Fixing date 0 decisions, investment at date 1 falls ( $\theta$ falls), (ii) Firms at date 0 reduce investment in $k$.

Proof: (i) Return to the left panel of figure 2, and run the experiment of shifting the demand curve from the high to the low $\lambda_{d}$. Alternatively, see the debt constraint of (5). (ii) See the appendix for the algebra. The idea is that since $\lambda_{d}$ enters only $V^{l}$, multiplicatively with $k$, firms recognize that domestic investment is less collateralizable in the $l$-state and therefore reduce date 0 investment. 
The underinvestment result is the same as that in Bernanke and Gertler (1989) or Kiyotaki and Moore (1997). It is underinvestment relative to a first best in which no collateral constraints are imposed. The inefficiency is that distressed firms who have a high marginal product investment $(\Delta)$ do not have the resources to take advantage of this investment. Its also easy to see that welfare must be increasing in $\lambda_{d}$.

The reason we used quotations in the proposition is that while choices are inefficient relative to the first best, they are still constrained efficient. A central planner, subject to these same collateral constraints, also has no mechanism to persuade foreigners and intact firms beyond the distressed firms' collateral.

We consider a central planner who makes choices to maximize the equally weighted sum of utilities of the domestic agents, subject to the constraints imposed by assumptions $1-3$. Since domestics are ex-ante identical, this objective amounts to maximizing the utility of any domestic firm at date 0 . The only complication is imposing the collateral constraints on the central planner.

\section{Definition 1 (Constrained Optimality)}

Let the solutions of $\left(P_{4}\right)$ be $\left(\hat{k}, \hat{d}_{0, f}\right)$, and let the welfare corresponding to these choices be $\hat{u}$. The competitive equilibrium is constrained Pareto optimal if a planner who directly makes date 0 choices of $\left(k, d_{0, f}\right)$, subject to the international collateral constraint of $d_{0, f} \leq \lambda_{f}^{l} w$, but lets debt markets clear competitively at date 1 , cannot raise welfare above $\hat{u}$.

By allowing markets to clear competitively at date 1, we impose the domestic and international collateral constraints at date 1 . Thus the central planner's program is only to choose $\left(k, d_{0, f}\right)$ subject to the date 0 international collateral constraint.

\section{Proposition 3 (Constrained Optimality)}

The competitive equilibrium solutions, $\left(\hat{k}, \hat{d}_{0, f}\right)$, are constrained Pareto optimal.

Proof: By inspection. Note first that prices $\left(L^{\omega}\right)$ do not appear anywhere in (P4). Then note that the central planner's program must be identical to (P4).

\section{Aggregate Collateral Constraint and Underprovision}

In the wasted collateral region, the fact that the economy has limited aggregate international collateral has no consequence since the constraints on domestic and foreign borrowing are substitutable with no effect on outcomes. The only cost of having an undeveloped domestic financial market is that collateral is not aggregated properly, resulting in lower investment and output. However, limited international collateral seems to be an important constraint in emerging economies. Indeed crises in these economies are times when interest rates rise 
rather than fall - a symptom that our model associates with a binding aggregate collateral constraint (see proposition 1).

In this section we show that the domestic credit constraint is even more costly if the aggregate international collateral constraint also binds. In particular, we show that there is a dynamic effect whereby agents undervalue international collateral, overborrow at date 0 , so that at date 1 they have less international collateral (relative to a constrained efficient outcome). Effectively, a low $\lambda_{d}$ interacts and tightens the aggregate collateral constraint so that the negative shock causes investment and output to fall too much at date 1.

\subsection{International collateral undervaluation}

We assume that the $h$ state leaves the economy in region I where neither of the collateral constraints bind, while the $l$ state leaves the economy in region IV where both collateral constraints bind. In the $h$ state, the profits for intact and distressed firms are as in the previous section. That is the intact firm profits,

$$
V_{i}^{h}=R k+\lambda_{f}^{h} w-d_{0, f}
$$

while the distressed firm has date 2 profits of,

$$
V_{s}^{h}=R k-k+\lambda_{f}^{h} w-d_{0, f}
$$

In the $l$ state, the domestic interest rate of $L^{l}$ rises above one. Thus intact firms earn a premium on their lending to distressed firms as $L^{l}>1$. Profits are,

$$
V_{i}^{l}=R k+L^{l}\left(\lambda_{f}^{l} w-d_{0, f}\right) .
$$

For the distressed firm, the cost of the higher interest rates is that their domestic collateral is worth less, lowering reinvestment. The profits are,

$$
V_{s}^{l}=r k+(\Delta-1) \theta^{l} k+\left(\lambda_{f}^{l} w-d_{0, f}\right)
$$

where,

$$
\theta^{l} k=\frac{\lambda_{d} r k}{L^{l}}+\lambda_{f}^{l} w-d_{0, f}
$$

Since a firm can be distressed or intact with equal probability, we can write the expected profits in the $l$ state as,

$$
\begin{aligned}
V^{l}= & \frac{R+r}{2} k+\lambda_{f}^{l} w-d_{0, f} \\
& +\frac{1}{2}(\Delta-1) \theta^{l} k+\frac{1}{2}\left(L^{l}-1\right)\left(\lambda_{f}^{l} w-d_{0, f}\right)
\end{aligned}
$$

The first line of the RHS in (7) reflects the expected profits, in the $l$ state, generated by date 0 investment net of foreign debt contracted at date 0 . In particular, this line 
corresponds to the expected wealth assuming that all distressed production units are allowed to fail. The value of saving these production units is captured in the next line. With probability of one-half, the firm is distressed and it borrows to save its own production units, directly earning the internal return of $\Delta$ against its collateral. With probability onehalf the firm is intact in which case it borrows against its international collateral and lends to the distressed firm, thereby earning the domestic interest rate of $L^{l}$.

The difference between the internal return of $\Delta$ for the distressed firm, and the external return of $L^{l}$ for the intact firm is the source of international collateral undervaluation. To see this, let us construct two different versions of $V^{l}$; one for individual firms and the other for a central planner. To construct the former, we simply substitute into (7) the expression for reinvestment implied by the microeconomic domestic collateral constraint, (6). This yields,

$$
V^{l}=\frac{R+r}{2} k+\frac{1}{2}\left(\Delta+L^{l}\right)\left(\lambda_{f}^{l} w-d_{0, f}\right)+\frac{\lambda_{d} r k}{2 L^{l}}\left(\Delta-L^{l}\right)
$$

To construct the central planner's version, which we denote by $V^{l *}$, we substitute instead the equilibrium collateral constraint on reinvestment. We know that in aggregate, reinvestment must be equal to the total international collateral of the economy. Thus,

$$
\theta^{l} k=2\left(\lambda_{f}^{l} w-d_{0, f}\right) .
$$

Substituting this expression into (7) we find,

$$
V^{l *}=\frac{R+r}{2} k+\Delta\left(\lambda_{f}^{l} w-d_{0, f}\right)
$$

The difference between these expressions highlights the undervaluation effect:

$$
V^{l}-V^{l *}=s_{d}^{l}\left(\frac{\lambda_{d} r k}{2 L^{l}}-\frac{\lambda_{f}^{l} w-d_{0, f}}{2}\right)
$$

At a given equilibrium, $V^{l}$ and $V^{l *}$ must be equal. But it is apparent that individuals and the central planner value a marginal unit of international collateral and domestic collateral quite differently. In particular:

- Individual firms value domestic collateral more than the central planner.

- Individual firms value international collateral less than the central planner.

- The divergence in these valuations are proportional to the domestic spread, $s_{d}^{l}$, which rises with declines in $\lambda_{d}{ }^{6}$

\footnotetext{
${ }^{6}$ It is easy to show that the term in parentheses in (8) does not (fully) offset the change in the spread as $\lambda_{d}$ falls. Starting with a local argument, take $d_{0, f}$ (and hence $k$ ) as given and reduce $\lambda_{d}$; then $L$ must fall proportionally with $\lambda_{d}$ (see (3)) so their ratio remains constant and so does the expression in parentheses. Now, in equilibrium $d_{0, f}$ rises so the expression in parentheses declines with a fall in $\lambda_{d}$. But since $d_{0, f}$ will rise only if the distortion increases, the rise in the spread must be larger than the decline in the term in parentheses.
} 
At the aggregate level, the central planner only values international collateral. This is because international collateral is all that can be used to attract foreign investment, and at date 1 the binding constraint is the inflow of foreign investment. However at the microeconomic level, both domestic collateral and international collateral can be used to secure financing. This is the basic tension between the individual and the central planner's problem.

A positive domestic spread heightens this tension by placing a wedge between the social and private valuation of collateral. A unit of international collateral generates a social return of $\Delta$ at date 1 , while a unit of domestic collateral generates a social return of one at date 1. At the individual level, for an intact firm, a unit of domestic collateral generates a return of one. On the other hand, a unit of international collateral only generates a return of $L^{l}$. The difference between social and private valuation of $s_{d}^{l}=\Delta-L^{l}$ results in undervaluation of international collateral. Domestic underdevelopment prevents collateral demanders (distressed firms) from transferring the full marginal value of collateral to the collateral providers (intact firms), since the demanders simply have insufficient collateral. ${ }^{7}$ As a result, at date 0 , firms will undervalue international collateral since if they are the lenders at date 1 , they will not share in the full surplus of reinvestment.

Underdeveloped financial markets (low values of $\lambda_{d}$ ) result in high domestic spreads and the systematic mis-valuation of collateral. The externality we have described is not of the traditional Bardhan-Harberger type, where individual borrowers do not internalize the fact that the country faces an upward sloping supply of foreign loan. Indeed, in our setup the economy does face a very steep international funds supply, for the country is rationed after some point, but the externality arises only when domestic financial markets are underdeveloped as well.

\subsection{Date 0 Problem}

Let us now state this result on the undervaluation of international collateral and its dependence on the underdevelopment of domestic financial markets more formally. We shall first write down the problem for the decentralized equilibrium, and then write down the central planner's program - in the same way as in the last section, i.e. a central planner who chooses $\left(k, d_{0, f}\right)$ and lets markets clear competitively at date 1.

The program for a firm at date 0 follows closely from the previous derivations. The

\footnotetext{
${ }^{7}$ Overvaluation of domestic collateral is the necessary counterpart of undervaluation of international collateral. At the individual firm level, for a distressed firm, a unit of international collateral still generates a return of $\Delta$. On the other hand, a unit of domestic collateral is discounted at the interest rate of $L^{l}$ and generates output of $\Delta$, providing a return of $s_{d}^{l}>0$. At the social level, domestic collateral generates an excess return of zero. At the individual firm level, this mis-pricing causes firms to overvalue the $\lambda_{d} r k$ of domestic collateral, resulting in too much domestic collateral relative to international collateral.
} 
expected value to being in the high state is,

$$
V^{h}=\lambda_{f}^{l} w-d_{0, f}+R k-k / 2
$$

Then using the $V^{l}$ that we just derived, yields the firm's program:

$$
\begin{aligned}
(P 5) \quad \max _{k, d_{0, f}} & \sum_{\omega \in\{l, h\}} \pi^{\omega} V^{\omega} \\
\text { s.t. } & V^{h}=\lambda_{f}^{l} w-d_{0, f}+R k-k / 2 \\
& V^{l}=\frac{R+r}{2} k+\frac{1}{2}\left(\Delta+L^{l}\right)\left(\lambda_{f}^{l} w-d_{0, f}\right)+\frac{\lambda_{d} r k}{2 L^{l}}\left(\Delta-L^{l}\right) \\
& c(k)=d_{0, f} \\
& d_{0, f} \leq \lambda_{f}^{l} w
\end{aligned}
$$

To arrive at the central planner's program we use $V^{l *}$ instead, and note also that $V^{h *}=V^{h}$ :

$$
\begin{aligned}
\text { (P6) } \max _{k, d_{0, f}} & \sum_{\omega \in\{l, h\}} \pi^{\omega} V^{\omega} \\
\text { s.t. } & V^{h *}=\lambda_{f}^{l} w-d_{0, f}+R k-k / 2 \\
& V^{l *}=\frac{R+r}{2} k+\Delta\left(\lambda_{f}^{l} w-d_{0, f}\right) \\
& c(k)=d_{0, f} \\
& d_{0, f} \leq \lambda_{f}^{l} w
\end{aligned}
$$

Proposition 4 (Constrained Optimality) Let $\left(k^{*}, d_{0, f}^{*}\right)$ be solutions to (P6). (a) These solutions are the constrained Pareto optimal date 0 choices of the economy. (b) $\left(k^{*}, d_{0, f}^{*}\right)$ are independent of the strength of domestic financial links, $\lambda_{d}$.

Proof: Part $(a)$, as before. Part (b) is apparent from inspection of program (P6). Since none of the constraints depend on the value of $\lambda_{d}$, the solution to the program will not either.

The second part of this proposition is particularly interesting because it says the central planner's choices are invariant to $\lambda_{d}$. However since the domestic spread is a decreasing function of $\lambda_{d}$ we know that the decentralized equilibrium will be a function of $\lambda_{d}$ and moreover the distortion will be decreasing in $\lambda_{d}$.

Proposition 5 (Undervaluation of International Collateral) Let $\left(\hat{k}, \hat{d}_{0, f}\right)$ be solutions to the program (P5) in the case when $L^{h}=1, L^{l}>1$ and $s_{d}^{l}>0$. Then the decisions, $\left(\hat{k}, \hat{d}_{0, f}\right)$, are constrained Pareto inefficient. A central planner can effect a Pareto improvement by perturbing these decisions to $\left(k^{\prime}, d_{0, f}^{\prime}\right)$, where $d_{0, f}^{\prime}<\hat{d}_{0, f}$ (hence $k^{\prime}<\hat{k}$ ).

Proof: see appendix

The proof follows closely from the logic laid out in the previous section. Note that the only difference between (P5) and (P6) is in the expressions for $V^{l}$ and $V^{l *}$. When the domestic spread, $s_{d}^{B}$, equals zero, there is no difference between the central planner's and the decentralized solution. In this case, the market equilibrium is constrained Pareto efficient. 
However, as $\lambda_{d}$ falls, at some point it must be that $s_{d}^{B}>0$ and there is a divergence in the social and private value of collateral, resulting in the inefficiency. The next proposition formally states the dependence of welfare on $\lambda_{d}$.

Proposition 6 (Financial market development and Welfare) In the decentralized equilibrium, welfare is increasing in $\lambda_{d}$. In the central planning solution, welfare is invariant to $\lambda_{d}$.

Proof: see appendix

\subsection{Discussion}

Unlike region II, in region IV, domestic interest rates rise in the $l$-state at date 1 . The interest parity condition breaks down $\left(L^{l}-1>0\right)$ because foreigners reach their maximum lending capacity of $\lambda_{f}^{l} w$ to domestic firms, and are therefore unable to arbitrage this interest rate differential. With a little more notation, the rise in interest rates could also be mapped into a fall in asset prices or a depreciation of the exchange rate. ${ }^{8}$ All of these are aspects of crises in emerging markets.

The pecuniary externality arises only when $s_{d}^{l}>0$ and the international collateral constraint binds. Thus in region II, while $s_{d}^{l}>0$, the international constraint is slack, and in region III while the international constraint is binding, $s_{d}^{l}=0$. Indeed, though we have not focused on region III, this region corresponds to the case where domestic financial markets are perfect while the international constraint is binding. This is the case considered in, e.g. Atkeson-Rios Rull (1996) and other representative-agent / sovereign-constraint models, where there is no externality.

It may seem counterintuitive that the pecuniary externality arises because $L^{l}$ does not rise enough in the crisis - i.e. $s_{d}^{l}>0$, and the domestic interest rate does not reflect the marginal product of investment. But lending spreads are typically higher in crises than in normal times - so that the $s_{d}^{l}$ implication seems borne out. Part of the reason the result is counterintuitive is that in our model all surplus transfer between distressed and intact firms occurs through the price mechanism. The distortion in this transfer due to the domestic collateral constraint is measured by the domestic spread. In reality, some of this limited transfer occurs via non-price mechanisms as well - quantity rationing, default, extortion, etc.

\footnotetext{
${ }^{8}$ The equity value of domestic firms at date 1 is assets minus liabilities, which is $\frac{\lambda_{d} r k}{L^{\omega}}+\lambda_{f}^{\omega} w-d_{0, f}$. The rise in $L^{\omega}$ causes this to fall. Our model does not define an exchange rate, but their are two ways that one may proceed to do so. We could introduce a nominal asset at date 1 and price this asset. Then as long as the asset is also domestic collateral - which seems reasonable since we normally think that money demand is determined by domestics - the rise in $L^{\omega}$ would also cause a fall in the nominal exchange rate. Alternatively, one could introduce non-tradeable and tradeable goods at both dates 1 and 2, and as long as foreigners did not accept non-tradeable goods as collateral, we would arrive at a similar result on the real exchange depreciation.
} 
$L^{l}$ is a catchall for both price and non-price transfers. As a result, if non-price mechanisms also exist, then $L^{l}$ will understate the price response, and will not correspond perfectly to the interest rate.

In the wasted collateral region the only effect of low $\lambda_{d}$ is poor collateral aggregation, while in region IV, the only effect of low $\lambda_{d}$ is that firms arrive at date 1 with less international collateral than would be efficient. Both effects lead to lower date 2 output. However, the sharp separation between these two effects is because of a modeling abstraction. We have taken the supply curve of foreign funds to be perfectly elastic up to $\lambda_{f} w$ and completely inelastic beyond that point. It is possible to model a smoother supply curve, in which case region II and region IV would be blended. At all points, both the collateral aggregation and the undervaluation result would be present.

The existence of the externality begs two questions. Can the private sector contract among themselves to eliminate the inefficiency? If not, what is optimal government policy? We deal with the second question in Caballero and Krishnamurthy (2000a), and shall return briefly to policy issues in the conclusion.

As far as the first question, there could be mechanisms around the inefficiency. As in the previous section, insurance contracts signed at date 0 to transfer all liquidity to distressed firms would work. But we rule these out on grounds that the type of firm at date 1 is unobservable.

Another way to try and solve the problem is to "fix" the price at date 1 . Imagine that all firms got together and agreed that the interest rate on any loan contract at date 1 in the $l$ state would be set at $L=\Delta$. Then date 0 incentives would be aligned with efficiency. However this arrangement would be budget infeasible at date 1 since lenders must in total receive $\Delta\left(\lambda_{f}^{l} w-d_{0, f}\right)$ on their loans, while borrowers only have $\lambda_{d} r k$ of domestic collateral, and in region IV, it must be that $\lambda_{d} r k<\Delta\left(\lambda_{f}^{l} w-d_{0, f}\right)$. The only way around this problem is to agree ex-ante to transfer some of the domestic collateral from intact to distressed firms - but this is like the insurance that we have ruled because of unobservability of types.

A last mechanism worth discussing is a credit line arrangement akin to Diamond and Dybvig (1983)'s deposit contracts. Let us denote the privately optimal amount of international collateral to be held in the $l$ state as $C=\lambda_{f}^{l} w-d_{0, f}$, and the socially efficient amount to be $C^{*}$, where we know that $C^{*}>C$. Now suppose that all firms gave $\lambda_{d} r k$ of domestic collateral and $C$ of international collateral to the bank, with the arrangement that any firm that drew its credit line at date 1 would receive $C^{*}$ and any firm that drew its line at date 2 would receive $\lambda_{d} r k$. Then, if $\lambda_{d} r k>C^{*}$ it is optimal for intact firms to wait till date 2 , while if $\Delta C^{*}>\lambda_{d} r k$ distressed firms would draw down $C^{*}$ at date 1. Since in region IV,

$$
\Delta>\frac{\lambda_{d} r k}{C}>1
$$

choosing $C^{*}>C$ makes the arrangement is budget feasible, and can improve efficiency. 
The problem with the arrangement is that it is informationally intensive at date 1 and very fragile - for the same reason that Diamond-Dybvig is fragile (see Jacklin (1987)). First note that the effective interest rate offered by the bank that uses $C^{*}$ is $L^{*}$ which is less than $L$. Thus if the private sector was choosing $C$, their incentives would be even more distorted. Second, holding fixed every other firm joining the banking arrangement, a firm has the incentive to opt out of banking and invest on their own. In this case, if they are distressed they offer a return of $L>L^{*}$ to anyone delivering international collateral. As a result firms in the banking arrangement draw down their credit line and lend to the rogue firm. Alternatively, if the firm is intact, it simply offers to lend at the bank rate of $L^{*}$ to distressed firms, which they are happy to accept. The only way to rule out this deviation is to enforce that firms can contract only with other firms in the banking arrangement - a possibility that seems unlikely.

Each of the above solutions rely on some form of insurance across firms. While in the above paragraphs we have appealed to theoretical arguments to rule out such insurance, the short answer to the question of does the private sector contract away the externality is that empirically there is possibly partial insurance, but our model investigates the case in which there is none.

\section{Disintermediation}

The results of the last two sections can be summarized [loosely] as, in the wasted collateral region outcomes depend separately on domestic and international collateral; when the aggregate collateral constraint binds as well, both forms of collateral interact, so that outcomes depend on international collateral, which is effectively a function of domestic collateral. In this section we discuss the converse case in which the shock to $\lambda_{f}$ feeds into the available domestic collateral - i.e. the latter is effectively a function of international collateral.

\subsection{Collateral Aggregation}

Distressed firms access the international collateral of intact firms by borrowing from these firms against their domestic collateral. The implicit assumption in the preceding analysis is that this collateral aggregation is done in a perfectly functioning public debt market. Distressed firms issue debt claims in the domestic market secured by domestic collateral. Intact firms issue debt claims to foreign investors secured by international collateral. They then use the proceeds from this issue to purchase the debt claims of the distressed firms.

In emerging markets, liquid domestic debt markets are the exception rather than the rule. Invariably, the financial system is bank based - for good reasons: lack of investor protection and the necessity of monitoring to alleviate asymmetric information places banks at the center of the financial system. Banks issue claims to foreign investors against balance 
sheets that are partially backed by international collateral - both of the distressed and the intact firms. These funds are then channeled to the distressed firms. Implicitly, the intact firm extends credit to the distressed firms against their domestic collateral.

But unlike the immutable debt markets of the previous sections, when asset prices experience sharp falls, banks themselves run into trouble. As banks enter distress, the economy's ability to aggregate collateral is weakened, triggering further declines in asset prices and real activity. This endogenous disintermediation process and its feedback into real activity and asset prices fits conventional wisdom well. Arguably, some form of it plays a role in virtually every emerging market's external crisis. And at its worst it is reminiscent of Indonesia in the recent Asian crisis, Mexico during the tequila crisis, and Chile during the debt crisis of the early 80 s. $^{9}$

\subsection{The Banking System: Amplification and Financial Bottlenecks}

In this section we sketch a model whereby all aggregation at date 1 is done via the banking system. There is no domestic debt market. Distressed firms in need of funds take loans from banks. To attract these funds, banks offer deposits at a market determined interest rate. Intact firms become the depositors. They mortgage their international collateral to foreign investors and then deposit these funds in the banking system. By intermediating these transactions, the banking system serves to aggregate collateral. This is the only role of banks in our model - we do not provide an explicit microfoundation for the existence of intermediation.

Balance Sheets. Consider a representative bank in a competitive banking sector (of unit measure). We shall assume that entering date 1, the bank has assets consisting of loans to firms backed by domestic collateral, and no liabilities (for simplicity). ${ }^{10}$ Then given the market interest rate on loans of $L^{\omega}$, the value of capital (entering date 1 , in units of dollars) in the bank is,

$$
q_{b}^{\omega}=\frac{A}{L^{\omega}} .
$$

The net worth (assets minus liabilities) of distressed and intact firms need to be modified to reflect the additional bank loan liability:

$$
\lambda_{f}^{\omega} w+\frac{r k-A}{L^{\omega}}-d_{0, f}
$$

\footnotetext{
${ }^{9}$ See Gelos and Werner (1999) for a study of lending practices by Mexican banks during the postliberalization period. Among other things, they document the significant role played by banks in lending to manufacturing firms without access to foreign funds, and their reliance on domestic collateral. They argue that this mix contributed significantly to the collapse of the banking system during the 94-95 crisis.

${ }^{10}$ The purpose of this section is to highlight the potential date 1 bottleneck brought about by the deterioration in banks' balance sheets. There are several interesting date 0 issues which merit an extensive discussion but which would lengthen this section substantially. For example, one may ask why banks do not sign contingent contracts with borrowers and depositors.
} 
Capital Constraints. Without further assumptions, the preceding case of banks is identical to that of public debt markets with $\lambda_{d}$ equal to one - i.e. the banking system is a veil. We now introduce capital constraints that limit the capacity of the banking system to aggregate collateral.

At date 1 , a bank takes on debt from intact firms of $d_{1, d}^{b}$ and makes loans of $x_{1, d}^{b}$ to the distressed firms - all in units of face value of date 2 goods. Let $L^{\omega}$ represent the interest rate on loans, and $L_{D}$ represent the deposits' interest rates. If no other constraint is present, both of these are made at the single market interest rate of $L^{\omega}$, and the expected date 2 repayment to the bank from this operation is $\left(x_{1, d}^{b}-d_{1, d}^{b}\right) L^{\omega}$ (in units of face value of goods at date 2). We assume that capital constraints restrict the size of this operation. In particular,

$$
q_{b}^{\omega} \geq \alpha\left(A+x_{1, d}^{b}(\omega)\right),
$$

where $0<\alpha<1$ is the capital that banks must hold against making loans with date 2 face value of $x_{1, d}^{b}(\omega) .{ }^{11}$ If this constraint binds, $L_{X}$ is still equal to $L$ but $L_{D}$ falls to one since there is an excess supply of deposits but a scarcity of loanable funds.

Taking as given the market interest rate (on loans) of $L^{\omega}$, the problem of a bank at date 1 is,

$$
\begin{array}{lll} 
& \max _{x_{1, d}^{b}(\omega), d_{1, d}^{b}(\omega)} & A-d_{0, f}^{b}+\left(L^{\omega}-1\right) x_{1, d}^{b}(\omega)-\left(L_{D}^{\omega}-1\right) d_{1, d}^{b}(\omega) \\
\text { s.t. } & (i) & q_{b}^{\omega} \geq \alpha\left(A+x_{1, d}^{b}(\omega)\right) \\
& (i i) & \frac{x_{1, d}^{b}(\omega)}{L^{\omega}}-\frac{d_{1, d}^{b}(\omega)}{L_{D}^{\omega}} \geq 0
\end{array}
$$

The objective of the bank reflects profits from making loans of $x_{1, d}^{b}(\omega)$ at the interest rate of $L^{\omega}$ and taking deposits of $d_{1, d}^{b}(\omega)$ at the interest rate of $L_{D}^{\omega}$. Constraint $(i)$ is simply the capital constraint on banks. Constraint (ii) reflects the date 1 resource constraint: funds must be raised to make all loans.

Since the formal analysis of equilibrium is very similar to that of the previous sections, we relegate it to the appendix. Banks will lend as much as they can whenever $L^{\omega}>1$, while in equilibrium $L^{\omega}=1$ when demand for funds is less than loanable funds. Firms will behave exactly as in the previous sections. In fact, as long as constraint $(i)$ is not binding, the problem is entirely analogous to that of the previous section with $\lambda_{d}=1$. To keep matters simple, we shall proceed under the assumption that the domestic collateral constraint does not bind - this is the case that is derived in the appendix, and is the case

\footnotetext{
${ }^{11}$ In practice, capital adequacy requirements are based on both assets as well as liabilities. For example, BIS standards assign capital requirements to different assets held by banks. The liabilities of the bank are sorted (i.e. common stock, preferred stock) and weighted to determine the amount of capital held by the bank and hence ensure that the capital requirement is met. Capital requirements can be justified from first principles on the basis of moral hazard within the banking sector. See Holmstrom and Tirole (1997), for example.
} 
that is reflected in the figure. Panel (a) in figure 3 depicts this scenario. There are two regions, (i) and (ii), which are distinguished by whether or not the international collateral constraint binds.

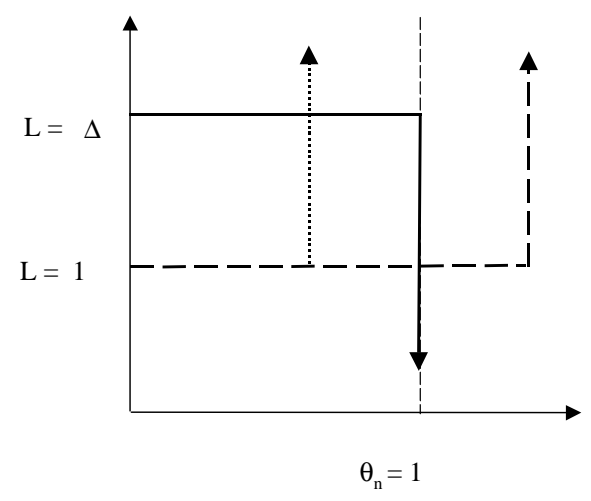

Panel (a) : Regions (i) and (ii)

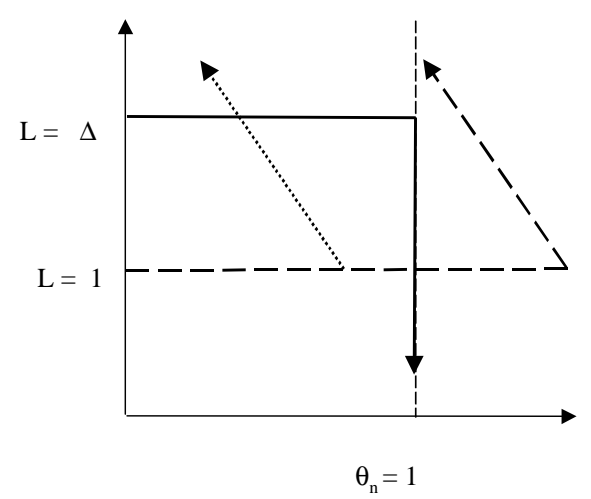

Panel (b) : Regions (iii) and (iv)

Figure 3: Equilibrium with Banks

The interesting new cases arise when the capital requirement $(i)$ does bind. In this case the economy can fall into regions (iii) or (iv) depending on how tightly it binds relative to demand from distressed firms. The dashed line in figure 6 (b) corresponds to a supply of loans which yields a region (iii) equilibrium: loan demand is fully satisfied, interest rates are low and output is high. Conversely, if loan supply is constrained by capital requirements, then interest rates rise to ration the scarce supply (dotted line, region (iv)). The key ingredient to highlight is that now the supply curve for loans bends backwards at the point where the capital requirement binds. This occurs because the value of banks' capital falls when interest rates rise (see equation (9)).

The backward bending nature of supply plays a significant role in region (iv), and differentiates it from region IV in section 2. While in both cases an aggregate collateral constraint and a microeconomic capital requirement bind, in the banking-intermediated case there is wasted collateral, in the sense that not all excess domestic resources are channeled to the distressed firms. Equilibrium is at point A rather than B, where the latter reflects full aggregation. Constrained banks become a financial bottleneck, which bring about 
simultaneously the worst of each scenario described in the previous sections: sharp declines in asset prices coupled with collateral waste.

\subsection{Multiple Equilibria}

The rise in domestic interest rates in region (iv) is not only a symptom of the crisis, it is also a cause of the crisis.

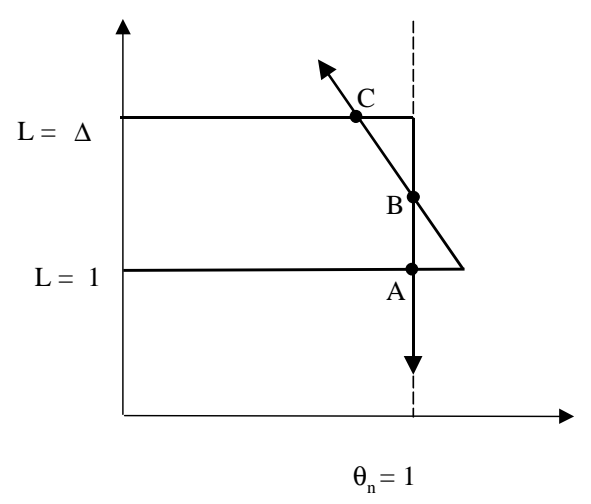

Figure 4: Multiple Equilibria with Banks

We illustrate this in figure 4. As we described above, the contraction in loan supply causes the rise in interest rates. The fall in domestic asset prices amplifies the impact of the crisis by deepening the credit crunch caused by banks' distressed balance sheets. ${ }^{12}$ But it is easy to see that the feedback between asset prices and feasible intermediation brings about the possibility of multiple equilibria.

\footnotetext{
${ }^{12}$ This amplification mechanism is similar in spirit to Kiyotaki and Moore (1997) in that a fall in asset prices is reinforced by a tightening financial constraint. However, an import difference between our approach and theirs lies in the identity of the agent with the crucial financial constraint. In Kiyotaki and Moore the financial constraint is on the demand side - constrained demand reduces the productivity of assets, causing the fall in asset prices, and further constraining demand. However, in our model the key financial constraint is on the supply side - constrained supply causes interest rates to rise, causing bank capital to be compromised, and further constraining supply. In this sense, our model is closer to the amplification mechanism studied in Krishnamurthy (1999).
} 
Points (A) and (B) in the figure represent two equilibria which are distinguished by low interest rates, non-binding capital requirements (A) and high interest rates, credit crunch (C). Point (B) is also a possibility in which interest rates rise to constrain loan supply to exactly meet demand. While in both (A) and (B) all production units are saved, this is not so in (C). The equilibrium in (C) is Pareto inferior to that of (A) and (B). More generally, with $\lambda_{d}<1$ or a concave but not rectangular demand function, equilibria can be strictly Pareto ranked. Low interest rate equilibria are more efficient than high rate ones.

\section{Final Remarks}

This paper has presented a model that highlights financial factors behind crises in emerging markets. While we are not the first to point out some of these factors - in particular that financial underdevelopment can lead to wasted collateral, as well as to the possibility that falling asset prices can lead to disintermediation - our approach is novel on two counts. First, we are able to study the effects of domestic and international financial constraints in a simple unified framework. Independently, both sets of constraints seem meaningful in the context of emerging markets, and appear in different forms in the literature. We have found that distinguishing between domestic and international collateral, and understanding how and when they interact, is useful in thinking through crises. Second, we show that domestic financial market underdevelopment, in a dynamic context, will lead to the undervaluation of international collateral.

We think that the collateral undervaluation result is particularly helpful in thinking through precautioning (i.e. date 0) questions in emerging markets. Observers have pointed to a number of vulnerability factors - balance sheet maturity mismatches caused by excessive short term debt, currency mismatches caused by contracting foreign currency debt, shortages of public and private reserves, to name a few. Yet there has been little said about why firms make choices that lead to such vulnerabilities. In Caballero and Krishnamurthy (2000b), we ask the question of why firms, knowing the possibility of balance sheet mismatches, choose to contract foreign currency debt. We show that contracting foreign currency debt is akin to contracting away international collateral. Thus our result is that if domestic financial markets are underdeveloped, firms will undervalue international collateral and choose excessive dollar liabilities. ${ }^{13}$ Indeed we think that a number of these vulnerability factors can be restated as ones that reduce international collateral, and thus our results points out that vulnerability is structural to emerging markets.

The results are also helpful in providing policy guidance. First of all the model identifies the primitive behind the incidence of crises as the shortage of international collateral.

\footnotetext{
${ }^{13}$ We also connect domestic financial market underdevelopment to the reluctance of foreign investors to enter the domestic lending business.
} 
Purely from an accounting standpoint, by sorting on their effects on international collateral, the model helps us to classify and order the different vulnerability factors that others have pointed out. More interestingly, since the collateral undervaluation result stems from an externality, a natural line of inquiry is in the design of policies to alleviate the externality. The policies that emerge are all ex-ante ones - i.e. precautions at date 0, rather than prescriptions of monetary policy during the date 1 crisis. In Caballero and Krishnamurthy (2000a), we study the effectiveness of sterilization as a policy response to date 0 capital inflows. Since the model motivates both the need for policy as well as models its implementation, we are able to characterize when policy leads to Pareto gains, and when it leads to Pareto losses. ${ }^{14}$

There are a number of related precautioning policy questions that the framework will provide guidance on. For example, the question of which of the private or public agents should hold international reserves, or the differential effects of domestic reserve requirements and foreign liquidity requirements. And, once extended to incorporate nominal assets, the framework will shed light on the role played by financial underdevelopment in the design of optimal exchange rate arrangements. We are currently working on these extensions.

\footnotetext{
${ }^{14}$ Our analysis is guided by the effect of policy on international collateral - does the private sector's reaction to a policy lead to a gain or loss in international collateral. A result which we find striking is that when the government bond market is illiquid, sterilization policy (swapping reserves for government bonds) may lead to a fall in the spread between corporate lending rates and government bond rates. This causes the private sector to overborrow from foreign lenders at date 0 - the opposite of what optimal policy would dictate.
} 


\section{Appendix}

\subsection{Incentive Constraints}

One possible formulation to justify agents' borrowing constraints is as follows. Consider a contract between a firm and a lender at date 0. Suppose that a firm investing one unit at date 0 yields date 2 flows of $\tilde{R}_{t}$ where $E\left[\tilde{R}_{t}\right]=R_{t}$, and the support of $\tilde{R}_{t}$ is $[0, \infty)$. Now assume that the realization of $\tilde{R}_{t}$ is private information of the firm. A lender can observe this payment only by paying a cost of $c$. Then, it is fairly standard to show that an optimal contract will be a debt contract (see Gale and Hellwig (1985)). The contract will specify a face of $f$; if $\tilde{R}_{t}>f$ the firm makes the repayment of $f$; otherwise, the firm defaults and lenders pay the audit cost and receive $\tilde{R}_{t}-c$.

Assume that each firm has a continuum of such projects each with i.i.d. return of $\tilde{R}_{t}$. Each project is individually financed via a debt contract. Then define,

$$
\theta_{t}=\frac{E\left[\tilde{R}_{t}-f \mid \tilde{R}_{t}>f\right] \operatorname{Prob}\left[\tilde{R}_{t}>f\right]}{R_{t}}<1
$$

This is the share of each firm that the entrepreneur necessarily holds. Lenders receive expected flows of,

$$
E\left[\tilde{R}_{t}-c \mid \tilde{R}_{t}<f\right] \operatorname{Prob}\left[\tilde{R}_{t}<f\right]+f \operatorname{Prob}\left[\tilde{R}_{t}>f\right]
$$

scaled by $R_{t}$ this is,

$\frac{E\left[\tilde{R}_{t}-f \mid \tilde{R}_{t}<f\right] \operatorname{Prob}\left[\tilde{R}_{t}<f\right]}{R_{t}}-c \frac{\operatorname{Prob}\left[\tilde{R}_{t}<f\right]}{R_{t}}+f \operatorname{Prob}\left[\tilde{R}_{t}>f\right]=1-\theta_{t}-c \frac{\operatorname{Prob}\left[\tilde{R}_{t}<f\right]}{R_{t}}$

This is the component of firms that can be held by outsiders. In our formulation we have suppressed the cost $c$, so that this component is simply the complement of what the firm holds itself.

\subsection{Proof of Proposition 2}

First of all note that the constraint $d_{0, f} \leq \lambda_{f}^{l} w$ will never bind. The reason is that if it did, then $L=\Delta$ at date 1 , and since we have assumed that date 1 reinvestment is sufficiently profitable relative to date 0 investment, firms would not saturate their budget constraint at date 0 . Given this, let us substitute $d_{0, f}=c(k)$ in the objectives.

The max problem for the firm at date 0 is,

$$
\max _{k} \pi^{h}\left(\lambda_{f}^{h} w-c(k)+R k-k / 2\right)+\pi^{l}\left(\frac{R+r}{2} k+\frac{\lambda_{d} r k}{2}(\Delta-1)+\frac{1}{2}(\Delta+1)\left(\lambda_{f}^{l} w-c(k)\right) .\right.
$$

The FOC for this problem is,

$$
\pi^{h}\left(-c^{\prime}(\hat{k})+R-1 / 2\right)+\pi^{l}\left(\frac{R+r}{2}+\frac{\lambda_{d} r}{2}(\Delta-1)-\frac{1}{2}(\Delta+1) c^{\prime}(\hat{k})\right)=0 .
$$

Let $\hat{k}\left(\lambda_{d}\right)$ be the solution to this equation. Since, $c(k)$ is strictly convex, $\hat{k}\left(\lambda_{d}\right)$ is increasing in $\lambda_{d}$. 


\subsection{Proof of Proposition 5}

For the decentralized equilibrium,

$$
\max _{k} \pi^{h}\left(\lambda_{f}^{h} w-c(k)+R k-k / 2\right)+\pi^{l}\left(\frac{R+r}{2} k+\frac{\lambda_{d} r k}{2 L^{l}}\left(\Delta-L^{l}\right)+\frac{1}{2}\left(\Delta+L^{l}\right)\left(\lambda_{f}^{l} w-c(k)\right) .\right.
$$

And for the central planning problem,

$$
\max _{k} \pi^{h}\left(\lambda_{f}^{h} w-c(k)+R k-k / 2\right)+\pi^{l}\left(\frac{R+r}{2} k+\Delta\left(\lambda_{f}^{l} w-c(k)\right) .\right.
$$

Since $c(k)$ is strictly convex, and the objective is linear, the FOC is necessary and sufficient for an optimum. To compare the decentralized and central planner's solutions, we can simply compare the FOC's. The decentralized equilibrium FOC is,

$$
\pi^{h}\left(-c^{\prime}(\hat{k})+R-1 / 2\right)+\pi^{l}\left(\frac{R+r}{2}+\frac{\lambda_{d} r}{2 L^{l}}\left(\Delta-L^{l}\right)-\frac{1}{2}\left(\Delta+L^{l}\right) c^{\prime}(\hat{k})\right)=0 .
$$

While the central planner's FOC is,

$$
\pi^{h}\left(-c^{\prime}\left(k^{*}\right)+R-1 / 2\right)+\pi^{l}\left(\frac{R+r}{2}-\Delta c^{\prime}\left(k^{*}\right)\right)=0 .
$$

It is clear that as long as $\Delta-L^{l}>0, k^{*}<\hat{k}$.

\subsection{Proof of Proposition 6}

First note that the central planner's solution is independent of $\lambda_{d}$, and that $\hat{k}>k^{*}$. Then all we need to show is that $\hat{k}\left(\lambda_{d}\right)$ is decreasing.

The FOC for the decentralized problem is,

$$
F\left(\hat{k}, \lambda_{d}\right) \equiv \pi^{h}\left(-c^{\prime}(\hat{k})+R-1 / 2\right)+\pi^{l}\left(\frac{R+r}{2}+\frac{\lambda_{d} r}{2 L^{l}}\left(\Delta-L^{l}\right)-\frac{1}{2}\left(\Delta+L^{l}\right) c^{\prime}(\hat{k})\right)=0 .
$$

where,

$$
L^{l}=\frac{\lambda_{d} r k}{\lambda_{t}^{l} w-d_{0, f}}
$$

Then, we wish to show that,

$$
\frac{d \hat{k}}{d \lambda_{d}}=-\frac{\frac{\partial F}{\partial \lambda_{d}}}{\frac{\partial F}{\partial \hat{k}}}<0 .
$$

After some algebra we can show,

$$
\frac{\partial F}{\partial \hat{k}}=-c^{\prime \prime}(\hat{k})\left(\pi^{h}+\pi^{l} \frac{\Delta+L^{l}}{2}\right)-\frac{\partial L^{l}}{\partial \hat{k}} \frac{1}{2}\left(\lambda_{d} r \frac{\Delta}{L^{2}}+c^{\prime}(\hat{k})\right)<0 .
$$

Also,

$$
\frac{\partial F}{\partial \lambda_{d}}=-\pi^{l} \frac{1}{2}\left(r+c^{\prime}(k) \frac{L^{l}}{\lambda_{d}}\right)<0 .
$$

Combining the above results, we can conclude that $\hat{k}\left(\lambda_{d}\right)$ is decreasing in $\lambda_{d}$. 


\subsection{Supporting Formulae for Banking Section}

The solution to program $(P 7)$ is determined by the binding constraints. Constraint $(i)$ requires that loans satisfy,

$$
A+x_{1, d}^{b}(\omega) \leq \frac{q_{b}^{\omega}}{\alpha}
$$

Now given loans and deposits,

$$
q_{b}^{\omega}=\frac{A+x_{1, d}^{b}(\omega)}{L^{\omega}}-\frac{d_{1, d}^{b}(\omega)}{L_{d}^{\omega}}=\frac{A}{L^{\omega}}
$$

where the last step follows since the amount of funds raised from depositors $\left(\frac{d_{1, d}^{b}(\omega)}{L_{d}^{\omega}}\right)$ must equal the amount of funds lent to firms $\left(\frac{x_{1, d}^{b}(\omega)}{L^{\omega}}\right)$. Thus, if the capital constraint binds,

$$
x_{1, d}^{b}(\omega)=A\left(\frac{1}{\alpha L^{\omega}}-1\right)
$$

which is decreasing in $L^{\omega}$.

Turning next to the decisions of firms, demand for loans by distressed firms and deposits from intact firms follow from the same logic as before (see P1 and P2). Intact firms extend deposits to banks of $x_{1, d}(\omega)$ (face value of date 2 goods),

$$
\begin{aligned}
& L_{D}^{\omega}>1 \quad \Rightarrow \quad \frac{x_{1, d}(\omega)}{L_{D}^{\omega}}=\lambda_{f}^{\omega} w-d_{0, f} \\
& L_{D}^{\omega}=1 \quad \Rightarrow \quad x_{1, d}(\omega) \leq \lambda_{f}^{\omega} w-d_{0, f}
\end{aligned}
$$

We write the problem for distressed firms assuming that the domestic collateral constraint never binds. Distressed firms take out bank loans of $d_{1, d}(\omega)$ to save production units,

$$
\begin{aligned}
& \Delta>L^{\omega} \Rightarrow \frac{d_{1, d}(\omega)}{L^{\omega}}=\max \left[k-d_{1, f}^{\omega}, 0\right], \\
& \Delta=L^{\omega} \Rightarrow \frac{d_{1, d}(\omega)}{L^{\omega}} \leq \max \left[k_{n}-d_{1, f}^{\omega}, 0\right] .
\end{aligned}
$$

Vis-a-vis the previous analysis, market clearing conditions need to be modified slightly to take into account banks. The aggregate amount of deposits in banks must equal the aggregate deposits of the intact firms,

$$
d_{1, d}^{b}(\omega) \equiv D_{1, d}^{b}(\omega)=X_{1, d}(\omega) \equiv \frac{1}{2} x_{1, d}(\omega)
$$

Likewise, the total loan supply from banks must equal the new domestic debt issued by distressed firms,

$$
x_{1, d}^{b}(\omega) \equiv X_{1, d}^{b}(\omega)=D_{1, d}(\omega) \equiv \frac{1}{2} d_{1, d}^{\omega}
$$


Taken together and combined with the capital constraint on banks this implies that,

$$
\begin{aligned}
& \lambda_{t}^{\omega} w-d_{0, f} \leq \frac{q_{b}^{\omega}}{L^{\omega} \alpha}-\frac{A}{L^{\omega}} \Rightarrow d_{1, d}(\omega)=x_{1, d}(\omega) \\
& \lambda_{t}^{\omega} w-d_{0, f}>\frac{q_{b}^{\omega}}{L^{\omega} \alpha}-\frac{A}{L^{\omega}} \Rightarrow d_{1, d}(\omega)=x_{1, d}(\omega)=2\left(\frac{q_{b}^{\omega}}{\alpha}-A\right)
\end{aligned}
$$

Consider the first inequality. When the capital requirement on banks does not bind, banks aggregate domestic collateral perfectly - they channel all of the excess debt capacity of the intact firms to the distressed firms. The economy behaves exactly as if $\lambda_{n}=1$ in a public debt market (section 2.4). Asset prices and investment depend on the international collateral constraint,

$$
\begin{array}{lll}
k<2\left(\lambda_{t}^{\omega} w-d_{0, f}\right) & \Rightarrow \quad L^{\omega}=L_{D}^{\omega}=1 & \theta^{\omega}=1 \\
k \geq 2\left(\lambda_{t}^{\omega} w-d_{0, f}\right) & \Rightarrow \quad L^{\omega}=L_{D}^{\omega}=\Delta & \theta^{\omega}<1 .
\end{array}
$$

When the capital requirement $(i)$ binds, the economy can fall into regions (iii) or (iv) depending on how tightly it binds relative to demand from distressed firms. In this case, $L_{D}^{\omega}=1$ and:

$$
\begin{array}{ll}
\frac{1}{2}\left(k-\left(\lambda_{t}^{\omega} w-d_{0, f}\right)\right)<\frac{q_{b}^{\omega}}{\alpha}-A \quad \Rightarrow \quad L^{\omega}=1 & \theta^{\omega}=1 \\
\frac{1}{2}\left(k-\left(\lambda_{t}^{\omega} w-d_{0, f}\right)\right) \geq \frac{q_{b}^{\omega}}{\alpha}-A \quad \Rightarrow & L^{\omega}=\Delta
\end{array}
$$




\section{References}

[1] Aizenman, Joshua, "Country Risk, Incomplete Information and Taxes on International Borrowing," Economic Journal 99, March 1989, pp. 147-161.

[2] Allen, Franklin and Douglas Gale, "Limited Market Participation and Volatility of Asset Prices," American Economic Review 84(4), September 1994, pages 933-55.

[3] Allen, Franklin and Douglas Gale, "Financial Markets, Intermediaries, and Intertemporal Smoothing," Journal of Political Economy, 105(3), June 1997, pages 523-46.

[4] Bardhan, Pranab K., "Optimum Foreign Borrowing," in Karl Shell, ed., Essays on the Theory of Optimal Economic Growth: MIT Press, 1967, pp. 117-128.

[5] Bernanke, Ben and Mark Gertler, "Agency Costs, Net Worth, and Business Fluctuations," American Economic Review 79-1, March 1989, pp. 14-31.

[6] Bhattacharya, Sudipto, and Gale, Douglas M., "Preference Shocks, Liquidity, and Central Bank Policy", Barnett, William A., ed.; Singleton, Kenneth J., ed.. New approaches to monetary economics. International Symposia in Economic Theory and Econometrics series: Cambridge University Press 1987, pp. 69- 88.

[7] Blommestein, Hans J., "Institutional Investors, Pension Reforms and Emerging Securities Markets," IADB WP \# 359, November 1997.

[8] Bulow, Jeremy and Rogoff, Kenneth, "A Constant Recontracting Model of Sovereign Debt", Journal of Political Economy 97-1, February 1989, pp. 155-78.

[9] Caballero, Ricardo J. and Krishnamurthy, Arvind, "Emerging Markets Crises: An Assets Market Perspective," IMF WP, 1999.

[10] Caballero, Ricardo J. and Krishnamurthy, Arvind, "International Liquidity Management: Sterilization Policy in Illiquid Financial Markets," mimeo MIT, January 2000a.

[11] Caballero, Ricardo J. and Krishnamurthy, Arvind, "Dollarization of Liabilities: Underinsurance and Domestic Financial Underdevelopment," mimeo MIT, July 2000b.

[12] Calvo, Guillermo A., "Balance of Payment Crises in Emerging Markets," mimeo, Maryland, January 1998.

[13] Chang, Roberto and Andres Velasco, "Financial Crisis in Emerging Markets: A Canonical Model," mimeo Atlanta Fed, July 1998.

[14] Diamond, Douglas W. and Dybvig, Philip H., "Bank Runs, Deposit Insurance, and Liquidity," Journal of Political Economy 91-3, June 1983, pp. 401-19. 
[15] Dollar, David, and Mary Hallward-Driemeier, "Crisis Adjustment, and Reform: Results from the Thailand Industrial Survey," mimeo May 1998.

[16] Gale, Douglas and Martin Hellwig, "Incentive Compatible Debt Contracts: The OnePeriod Problem" Review of Economic Studies 52(4), October 1985, pp. 647-63.

[17] Gelos, R. Gaston and Alejandro M. Werner, "Financial Liberalization, Credit Constraints, and Collateral: Investment in the Mexican Manufactuing Sector," IMF WP/99/25, March 1999.

[18] Goldfajn, Ilan and Rodrigo O. Valdes, "The Twin Crises and the Role of Financial Intermediation," IMF mimeo, August 1998.

[19] Harberger, Arnold, "Lessons for Debtor-Country Managers and Policymakers," in J.Cuddington and G.Smith (eds.), International Debt and the Developing Countries. Washington: World Bank, 1985.

[20] Holmstrom, Bengt and Tirole, Jean, "Financial Intermediation, Loanable Funds, and the Real Sector," Quarterly Journal of Economics 112-3, August 1997, pp 663-91.

[21] Holmstrom, Bengt and Tirole, Jean, "Private and Public Supply of Liquidity," Journal of Political Economy 106-1, February 1998, pp. 1-40.

[22] Jacklin, Charles J., "Demand Deposits, Trading Restrictions, and Risk Sharing," Prescott, Edward C., ed.; Wallace, Neil, ed.. Contractual arrangements for intertemporal trade. Minnesota Studies in Macroeconomics series, vol. 1 Minneapolis: University of Minnesota Press 1987, pp. 26-47.

[23] Kang, Jun-Koo and Rene M. Stulz, "Why Is There Home Bias? An Anlysis of Foreign Portfolio Equity Ownership in Japan," Journal of Financial Economics 46-1, October 1997, pp. 3-28.

[24] Kehoe, Timothy, and David Levine, "Debt-constrained Asset Markets," Review of Economic Studies 60-4, October 1993, pp. 865-888.

[25] Kiyotaki, Nobuhiro and Moore, John, "Credit Cycles," Journal of Political Economy, 105-2, April 1997, pp. 211-48.

[26] Merton, Robert, "A Simple Model of Capital Market Equilibrium with Incomplete Information," Journal of Finance, 42-3, July 1987, pp 483-510.

[27] World Economic Outlook, IMF, May 1998.

[28] The World Bank, East Asia: The Road to Recovery, September 1998. 